\title{
The relationship between genetic variability and the susceptibility of Biomphalaria alexandrina snails to Schistosoma mansoni infection
}

\author{
Azza H Mohamed', Ahmed T Sharaf El-Din², Ahmed M Mohamed', Mohamed R Habib²/+ \\ 'Zoology Department, Faculty of Science, Menoufiya University, Shebin El-Kom, Egypt \\ ${ }^{2}$ Medical Malacology Laboratory, Theodor Bilharz Research Institute, PO Box 30 Imbaba, Giza, Egypt
}

In the present study, Biomphalaria snails collected from five Egyptian governorates (Giza, Fayoum, Kafr ElSheikh, Ismailia and Damietta), as well as reference control Biomphalaria alexandrina snails from the Schistosome Biological Supply Center (SBSC) (Theodor Bilharz Research Institute, Egypt), were subjected to species-specific polymerase chain reaction (PCR) assays to identify the collected species. All of the collected snails were found to be $\mathrm{B}$. alexandrina and there was no evidence of the presence of Biomphalaria glabrata. Randomly amplified polymorphic DNA (RAPD)-PCR assays showed different fingerprints with varying numbers of bands for the first generation $\left(F_{r}\right)$ of B. alexandrina snail populations (SBSC, Giza, Fayoum, Kafr El-Sheikh, Ismailia and Damietta). The primer OPA-1 produced the highest level of polymorphism and amplified the greatest number of specific bands. The estimated similarity coefficients among the B. alexandrina populations based on the RAPD-PCR profiles ranged from 0.56 (between SBSC and Ismailia snails) to 0.72 (between Ismailia and Kafr El-Sheikh snails). Experimental infection of the F, of progeny from the collected snails with Schistosoma mansoni (SBSC strain) showed variable susceptibility rates ranging from 15\% in the Fayoum snail group to $50.3 \%$ in SBSC snails. A negative correlation was observed between the infection rates in the different snail groups and the distances separating their corresponding governorates from the parasite source. The infection rates of the snail groups and their similarity coefficients with SBSC B. alexandrina snails were positively correlated. The variations in the rates of infection of different B. alexandrina groups with S. mansoni, as well as the differences in the similarity coefficients among these snails, are dependent not only on the geographical distribution of the snails and the parasite, but also on the genetic variability of the snails. Introduction of this variability into endemic areas may reduce the ability of the parasite to infect local hosts and consequently reduce schistosomiasis epidemiology.

Key words: Biomphalaria alexandrina - Schistosoma mansoni - RAPD-PCR - polymorphism - genetic variability - susceptibility

The geographic distribution of Schistosoma mansoni is closely tied to that of susceptible species of Biomphalaria snails, which support the development of the asexually reproducing sporocyst stages of this parasite (Frandsen 1979). One of the keys to understanding the present and future of S. mansoni in Egypt is obtaining additional information about the freshwater snails that play an indispensable role in its transmission. Identification of Biomphalaria species is important to better understand schistosomiasis epidemiology. Considering that morphological identification may become difficult or even impossible under certain circumstances, use of molecular-based methods has permitted the generation of more consistent information concerning the population structure of Biomphalaria, furthering knowledge regarding the taxonomy of and diagnosis of infection in these species. In studying schistosomiasis epidemiology, it is important to correctly identify host snail species because snail populations might be misidentified in some cases due to their morphological similarities as refractory species that do not constitute a host species (Caldeira et al. 2009).

+ Corresponding author: m_ramadanhabib@yahoo.com

Received 8 June 2011

Accepted 11 January 2012
Biomphalaria alexandrina has historically been implicated in the transmission of S. mansoni in Egypt. This snail species is very closely related to several other African Biomphalaria species constituting a Nilotic species complex found in the Nile River basin (DeJong et al. 2001). Historically, S. mansoni has been confined to the north central Nile Delta, while Schistosoma haematobium has been the predominant species within Egypt. Infections with $S$. haematobium were once common throughout parts of the country containing water channels. Over several decades, during which substantial changes in irrigation patterns have occurred, there have been major changes in the distribution of snail hosts and, hence, the pattern of schistosomiasis endemicity (Miller et al. 1981). Changes in the hydrology of the Nile basin, controlled water flows and new irrigation networks following construction of the High Dam at Aswan have increased the availability of still water habitats, which represent the ideal setting for the growth and reproduction of Biomphalaria snails (Vrijenhoek \& Graven 1992).

The situation with respect to Biomphalaria in Egypt has become complicated in recent years by the introduction of Biomphalaria glabrata. In 1996, snails identified morphologically as B. glabrata were found in many kilometres of irrigation canals and drains along certain areas of the Nile Delta (Yousif et al. 1996). Two years later, snails that were neither of the B. alexandrina or 
B. glabrata species were reported to be widespread throughout the Nile Delta. Morphological examination of hundreds of specimens of this type showed that they exhibit features in common with both $B$. alexandrina and B. glabrata. Therefore, these snails are considered to be a hybrid of the two species (Yousif et al. 1998a). Among the differentiating characters of these snails, it was found that in the case of $B$. glabrata, the head-foot appears faint greenish yellow in colour, while it is dark grey in both $B$. alexandrina and the hybrid. Both of these snails show dense black pigmentation on their mantle surface, while $B$. glabrata presents patchy pigmentation, especially close to the mantle edge. In median-sized snails, the radula pattern in B. alexandrina shows teeth numbers of 133-151 $\times 49$ for transverse and longitudinal rows, while in both B. glabrata and the hybrid snails they are (133-146 $\times 43)$. The mesocone of the lateral cone is simply triangular in $B$. alexandrina, while it is arrowhead-shaped in $B$. glabrata and the hybrid snails. In both $B$. alexandrina and the hybrid snails, the vergic sheath length is equal to that of the preputium, while in B. glabrata it is $20 \%$ longer than the preputium (Yousif et al. 1998a). Based on these data, Yousif et al. concluded that one of the new snail populations consists of hybrids of $B$. alexandrina and $B$. glabrata. Since that study, B. glabrata and the hybrids identified in comprehensive morphological and molecular studies have been reared at the Theodor Bilharz Research Institute (TBRI), Giza, Egypt. However, in 2005, a molecular survey was performed to identify the species of Biomphalaria present in Egypt. The survey concluded that there was no evidence of the presence of $B$. glabrata or of a species that was a hybrid of $B$. alexandrina and $B$. glabrata (Lotfy et al. 2005a).

The susceptibility of Biomphalaria to S. mansoni infection varies among snails according to their age, genetic variation, immune system status and the geographic areas in which both snails and the trematode occur (Richards \& Shade 1987). Research performed by Grosholz (1994) and Wiehn et al. (2002) has demonstrated that the establishment of parasites in intermediate hosts can vary significantly based on host genetics. In addition, Grech et al. (2006) extended this work to show that intermediate host genetics could potentially impact the transmission of parasite genotypes between hosts associated with a complex life cycle. Genetic predictability in Biomphalaria populations, in addition to the negative effects associated with inbreeding (such as the expression of deleterious alleles), could enhance $S$. mansoni infections in these populations and the subsequent transmission of this parasite to definitive human hosts. Introduction of genetic variability to snail populations via migration may reduce the parasite's ability to infect and exploit local hosts, decreasing parasite fitness and enhancing host fitness (Trouve et al. 2003, 2005).

In Brazil, there are three intermediate snail vectors and two potential hosts of $S$. mansoni. Previous studies detected three variant molecular profiles of Biomphalaria amazonica and demonstrated intraspecific variations using sequence data. To verify whether such differences might correspond to either B. amazonica or Biomphalaria cousini, Teodoro et al. (2010) performed morphological examination and molecular analyses using polymerase chain reaction-restriction fragment length polymorfism (PCR-RFLP) and sequencing. In addition, B. cousini were subjected to $S$. mansoni susceptibility experiments. The morphological data on Brazilian specimens predominantly matched the morphology described for B. amazonica. Additionally, the PCR-RFLP results also showed three variant molecular profiles for the specimens previously identified as $B$. amazonica and the phylogenetic analyses showed two groups, one similar to $B$. amazonica and another to $B$. cousini. Furthermore, $B$. cousini proved to be susceptible to $S$. mansoni. These results confirmed the occurrence of $B$. cousini in Brazil and indicated the risk of introducing schistosomiasis mansoni into new areas.

Random amplification of polymorphic DNA (RAPD) analysis has many uses in diverse fields of study, such as for assessment of genetic diversity among investigated species or classification of both plant and animal taxa. The fact that arbitrary primers are potentially capable of amplifying numerous loci in the genome and that the DNA fragments produced have a taxon-specific nature makes the RAPD technique particularly attractive for analysis of genetic distance and phylogeny reconstruction (Clark \& Lanigan 1993, Borowsky et al. 1995). DNA markers provide the opportunity to perform genetic characterisation and allow direct comparison of different genetic materials, independent of environmental influences (Ogunkanmi et al. 2009).

RAPD-PCR products can be interpreted as dominant single-locus markers that are inherited in a Mendelian fashion. In addition, the amplified fragments are primer specific but randomly distributed throughout the genome and therefore allow essentially unbiased sampling of genetic similarity among organisms (Welsh \& McClelland 1990, Williams et al. 1990). The RAPD technique has long been found to be useful for studying molluscan species. Several investigators have shown that RAPD-PCR is useful for examining differences both between and within different Biomphalaria snail species. The genetic diversities of B. glabrata and Biomphalaria pfeifferi, which are intermediate hosts of $S$. mansoni, have been analysed both within and between populations using RAPD (Vidigal et al. 1994, Langand et al. 1999). In addition, promising results concerning the use of RAPDPCR for genetically differentiating experimentally selected B. glabrata snails that are resistant and susceptible to $S$. mansoni miracidia have been reported by different authors (Larson et al. 1996, Knight et al. 1999, Lewis et al. 2003). In Africa, Webster et al. (1996) demonstrated the effectiveness of RAPD analysis for investigating intra-specific variation within a population of B. pfeifferi in Zimbabwe. Abdel-Hamid et al. (1999) used RAPD analysis to study the resistance of Biomphalaria tenagophila to S. mansoni. Furthermore, Oliveira et al. (2008) used RAPD-PCR to gather data indicating great genetic variability among susceptible and resistant strains both within and between B. glabrata and B. tenagophila using three different primers, while specimens from the same snail species showed few individual differences between the susceptible and resistant strains. 
The present study was undertaken to explore the role that genetic variation plays in the susceptibility of $B$. alexandrina snails from different Egyptian localities to $S$. mansoni using similarity coefficients and dendrogram trees generated from RAPD-PCR profiles.

\section{MATERIALS AND METHODS}

Collection of Biomphalaria - Biomphalaria snails were collected from populations in water courses in five Egyptian governorates (Giza, Fayoum, Kafr El-Sheikh, Ismailia and Damietta) (Fig. 1). The 6th investigated population consisted of $B$. alexandrina snails from the Schistosome Biological Supply Center (SBSC), TBRI, which served as a reference control. Additionally, B. glabrata snails were obtained from the Medical Malacology Laboratory (TBRI). These field snail populations, as well as their first offspring (F1), were used throughout this study.

Snail identification using species-specific PCR-DNA extraction - Three snails from each governorate's field population were dissected for DNA extraction as described by Winnepennickx et al. (1993) with some modification (Abdel-Hamid et al. 1999). Briefly, the snails'



Fig. 1: A map of Egypt showing the governorates from which Biomphalaria snails were collected. head-foot region was dissected out, powdered in liquid nitrogen using a mortar and pestle and transferred to a centrifuge tube containing $15 \mathrm{~mL}$ of pre-heated $\left(60^{\circ} \mathrm{C}\right)$ CTAB buffer $(2 \% \mathrm{w} / \mathrm{v}$ CTAB, $1.4 \mathrm{M} \mathrm{NaCl}, 0.2 \% \mathrm{v} / \mathrm{v}$ $\beta$-mercaptoethanol, $20 \mathrm{mM}$ EDTA, $100 \mathrm{mM}$ Tris $\mathrm{HCl} \mathrm{pH}$ $8,0.1 \mathrm{mg} / \mathrm{mL}$ proteinase $\mathrm{K}$ ). After incubation at $60^{\circ} \mathrm{C}$ for $30 \mathrm{~min}$, the suspension was extracted with an equal volume of phenol:chloroform:isoamyl alcohol (25:24:1). Following centrifugation $(8,000 \mathrm{rpm}, 10 \mathrm{~min})$, the aqueous phase was incubated with $5 \mathrm{~mL}$ RNase for $1 \mathrm{~h}$ at $37^{\circ} \mathrm{C}$. DNA was extracted with an equal volume of chloroform:isoamyl alcohol (24:1). After centrifugation ( $8,000 \mathrm{rpm}, 10 \mathrm{~min})$, the aqueous phase was transferred to a centrifuge tube. DNA was precipitated by adding a $\sim 2 / 3$ volume of isopropanol, gently inverting the tube and incubating it overnight at room temperature. DNA was then collected by centrifugation at $8,000 \mathrm{rpm}$ for $10 \mathrm{~min}$. The obtained DNA was washed in $76 \%$ ethanol, $10 \mathrm{mM}$ ammonium acetate for $30 \mathrm{~min}$ and recovered by centrifugation $(8,000 \mathrm{rpm}$, $10 \mathrm{~min}$ ). After air drying, the DNA was dissolved in 20 $\mu \mathrm{L}$ deionised water and the DNA concentration was estimated using $2 \%$ agarose gel electrophoresis.

DNA amplification - Two pairs of species-specific primers (Genetech, Egypt) were used as previously described by Lotfy et al. (2005b) (Table I). One primer pair (GITS2F1 and GITS2R1) was used to amplify an approximately $361 \mathrm{bp}$ fragment of B. glabrata internal transcribed spacer (ITS) 2 of the ribosomal DNA (ITS2), while a second primer pair (AITS1F1 and AITS1R1) was used to amplify a 316 bp fragment of $B$. alexandrina ITS1. The volume of each amplification reaction was $20 \mu \mathrm{L}$ and included approximately $200 \mathrm{ng}$ of DNA, $0.8 \mathrm{mM}$ dNTPs, $2 \mathrm{mM} \mathrm{MgCl}, 0.5 \mu \mathrm{M}$ each primer, 0.5 units of Taq DNA polymerase (Promega) and $2.5 \mu \mathrm{L}$ of $10 \mathrm{x}$ reaction buffer. The thermocycler (Whatman Biometra $\mathrm{T}$ Gradient) was programmed as follows with a $1^{\circ} \mathrm{C}$ per second rate of change: 1 cycle of $95^{\circ} \mathrm{C}$ for $1 \mathrm{~min}$, $62^{\circ} \mathrm{C}$ for $2 \mathrm{~min}$ and $74^{\circ} \mathrm{C}$ for $1 \mathrm{~min} 30 \mathrm{~s}$, followed by 30 cycles of $95^{\circ} \mathrm{C}$ for $30 \mathrm{~s}, 62^{\circ} \mathrm{C}$ for $30 \mathrm{~s}, 74^{\circ} \mathrm{C}$ for $1 \mathrm{~min}$ $30 \mathrm{~s}$, plus a final extension step for $7 \mathrm{~min}$.

Exposure of snails to miracidia - S. mansoni ova were obtained from SBSC from an Egyptian strain originally collected from Giza that has been routinely maintained in B. alexandrina and an albino Mus musculus

TABLE I

Species-specific primers used in the present study

\begin{tabular}{lcc}
\hline Amplified region & $\begin{array}{c}\text { Forward primer } \\
\text { (species-specific difference sites) }\end{array}$ & $\begin{array}{c}\text { Reverse primer } \\
\text { (species-specific difference sites) }\end{array}$ \\
\hline $\begin{array}{l}\text { Biomphalaria alexandrina ITS1 } \\
\text { species-specific primers }\end{array}$ & AITS1F1 (4 sites) & AITS1R1 (2 sites) \\
$\begin{array}{l}\text { Biomphalaria glabrata } \text { ITS2 } \\
\text { species-specific primers }\end{array}$ & 5'-TTGCTATCGACGATAACAGCAC-3' \\
GITS2F1 (7 sites) & 5'-AGGGGCATAGGTACCCTGGAAC-3' \\
GITS2R1 (12 sites)
\end{tabular}

ITS: internal transcribed spacer. 
CD1 strain. The ova were left to hatch in dechlorinated water $\left(24 \pm 1^{\circ} \mathrm{C}\right)$ under a desk lamp (Chernin 1970). Three replicates, each of which included 30 lab-bred B. alexandrina snails $(4-6 \mathrm{~mm})$ from offspring of the snails collected from each governorate as well as a control snail group from SBSC were individually exposed to ten newly hatched $S$. mansoni miracidia, which were suctioned using a micropipette according to Theron et al. (1997). From day 21 post-miracidial exposure, the snails were examined individually and repeatedly for cercarial shedding in multi dishes under artificial light for $2 \mathrm{~h}$ (stimulant period) using $2 \mathrm{~mL}$ of dechlorinated tap water/snail. After initial shedding was observed, the snails were screened individually once per week until their death. All snails that died during the prepatent period were crushed between two slides and inspected under a microscope to detect immature parasite stages (Chernin \& Dunavan 1962). The infection rate was calculated at the end of the experiment by dividing the number of shedding and positive crushed snails by the number of exposed snails and the survival rate was calculated by dividing the number of snails at first shedding by the total number of exposed snails (Yousif et al. 1998b). On the first day on which cercariae were detected, positive snails were separated individually into plastic cups. The cercariae produced per snail were transferred to a small Petri dish using a Pasteur pipette, fixed in Bouin's solution and counted under a stereomicroscope. This examination was repeated weekly.

$R A P D-P C R$ - Snail DNA was extracted from the offspring of snails from each governorate, as previously described, and RAPD-PCR reactions were conducted using four random primers (Matrix, Egypt) with the sequences shown in Table II. The reaction conditions were optimised and the mixtures ( $25 \mu \mathrm{L}$ total volume) contained the following components: $3 \mu \mathrm{L}$ dNTPs (2.5 mM), $2.5 \mu \mathrm{L} \mathrm{MgCl}_{2}(25 \mathrm{mM}), 2.5 \mu \mathrm{L} 10 \times$ buffer, $5.0 \mu \mathrm{L}$ primers $(10 \mathrm{mM}), 1.0 \mu \mathrm{L}$ template DNA $(50 \mathrm{ng} /$ $\mu \mathrm{L}), 0.2 \mu \mathrm{L}$ Taq polymerase ( 5 units $/ \mu \mathrm{L})$ and the remaining volume consisted of sterile distilled $\mathrm{H}_{2} \mathrm{O}$.

Amplification was performed in a thermocycler (Perkin Elmer 9700) programmed to perform an initial denaturation step at $95^{\circ} \mathrm{C}$ for $5 \mathrm{~min}$, followed by $40 \mathrm{cy}-$ cles of $95^{\circ} \mathrm{C}$ for $1 \mathrm{~min}$, annealing at $30^{\circ} \mathrm{C}$ for $1 \mathrm{~min}$ and polymerisation at $72^{\circ} \mathrm{C}$ for $1 \mathrm{~min}$, with a final extension step at $72^{\circ} \mathrm{C}$ for $10 \mathrm{~min}$.

\section{TABLE II}

List of the random primers used in random amplification of polymorphic DNA-polymerase chain reaction analysis and their nucleotide sequences

\begin{tabular}{lcc}
\hline Number & Name & Sequence $(5, \ldots \ldots \ldots \ldots \ldots \ldots . . . . . . .$. \\
\hline 1 & OPA-18 & AGGTGACCGT \\
2 & OPA-9 & GGGTAACGCC \\
3 & LROR & ACCCGCTGAACTTAAGC \\
4 & OPA-1 & CAGGCCCTTC \\
\hline
\end{tabular}

Detection and analysis of the amplified products Electrophoresis in an agarose gel is the standard method used to separate, identify and purify DNA fragments (Sambrook et al. 1989). This technique is simple, rapid to perform and capable of resolving fragments of DNA that cannot be separated adequately by other procedures, such as density gradient centrifugation. Furthermore, the location of DNA within the gel is determined directly by staining with a low concentration of the fluorescent intercalating dye ethidium bromide and bands containing as little as $10 \mathrm{ng}$ of DNA can be detected by direct examination of the gel in ultraviolet light. The size of the bands obtained via PCR in this study was determined using a 100 bp DNA ladder (Promega, USA).

Statistical analysis - The statistical analyses applied included calculation of the mean, standard deviation, standard error and a $t$ value at $\mathrm{p}<0.05$ (Zar 1999). These calculations were performed for both the control (SBSC snails) and other snail groups. Correlation, homogeneity, chi-square (continuity adjusted), analysis of variance (ANOVA) and linear regression analyses were conducted using SPSS version 11.5.0 (SPSS Inc, Chicago, IL). Data on the number of cercariae produced were square root transformed prior to statistical analyses to satisfy the distributional assumptions of the test. ANOVA was performed according to Sokal and Rohlf (1995) to analyse cercarial shedding, with one week as a repetition factor and parasitic infection as the treatment factor. The overall sample means for cercariae production were calculated and compared using the Student-Neuman-Keuls test for multiple pairwise comparisons of means.

The experimental infection rates of every snail group pair were compared by means of $2 \times 2$ contingency tables using the chi-square $\left(\chi^{2}\right)$ test or Fisher's exact test. Significant associations $(\mathrm{p}<0.05)$ between the infection rate and the distance between the source of parasites and the origin of snails were analysed with the Spearman correlation coefficient (r).

RAPD-DNA fragments were scored as 1 or 0 for the presence or absence of bands, respectively. Only sharp bands were scored ("ghost" bands were not scored). The obtained binary data were subjected to analysis with GelAnalyzer3 (Egygene) software. The genetic similarity among isolates was determined using Nie's genetic distance (Nie 1987). A dendrogram was constructed based on the matrix of genetic similarity employing the unweighted pair group method with arithmetic average (UPGMA). All calculations were performed with the NTSYS-pc 2.02 software package (Rohlf 2000).

\section{RESULTS}

Identification of Biomphalaria species using PCR - Species-specific PCR assays using B. glabrata ITS2 primers yielded the expected $361 \mathrm{bp}$ product for the laboratory control B. glabrata population (Medical Malacology Lab, TBRI), while no products were obtained for any of the Biomphalaria snail populations collected from the field (Fig. 2A). To ensure that all of the collected snails were $B$. alexandrina, three snail populations (Giza, Fayoum and Kafr El-Sheikh) were selected for the next species-specific PCR experiment. Positive results 
(316 bp product) were obtained for these snails using the $B$. alexandrina ITS1 primers, indicating that these snails are indeed B. alexandrina (Fig. 2B). According to the results of these assays, the Biomphalaria snails collected from the field were $B$. alexandrina and there was no evidence of the presence of $B$. glabrata. Positive and negative controls (using laboratory populations of each species) gave the expected results in all assays.

Experimental infection - The results of experimental infection of the $B$. alexandrina snail groups with $S$. mansoni are presented in Table III. Snails were classified depending on their infection rates according to the method of Saoud (1965), in which snails were considered refractory at an infection rate below $10 \%$, low susceptibility at $10-25 \%$, moderate susceptibility at $25-50 \%$ and high susceptibility at an infection rate over $50 \%$. The experimental snail groups were classified as follows: high susceptibility (SBSC), moderate susceptibility [Giza (43.3\%), Ismailia (20\%) and Kafr El-Sheikh (20\%)] and low susceptibility [Fayoum snails $(15 \%)$ ].
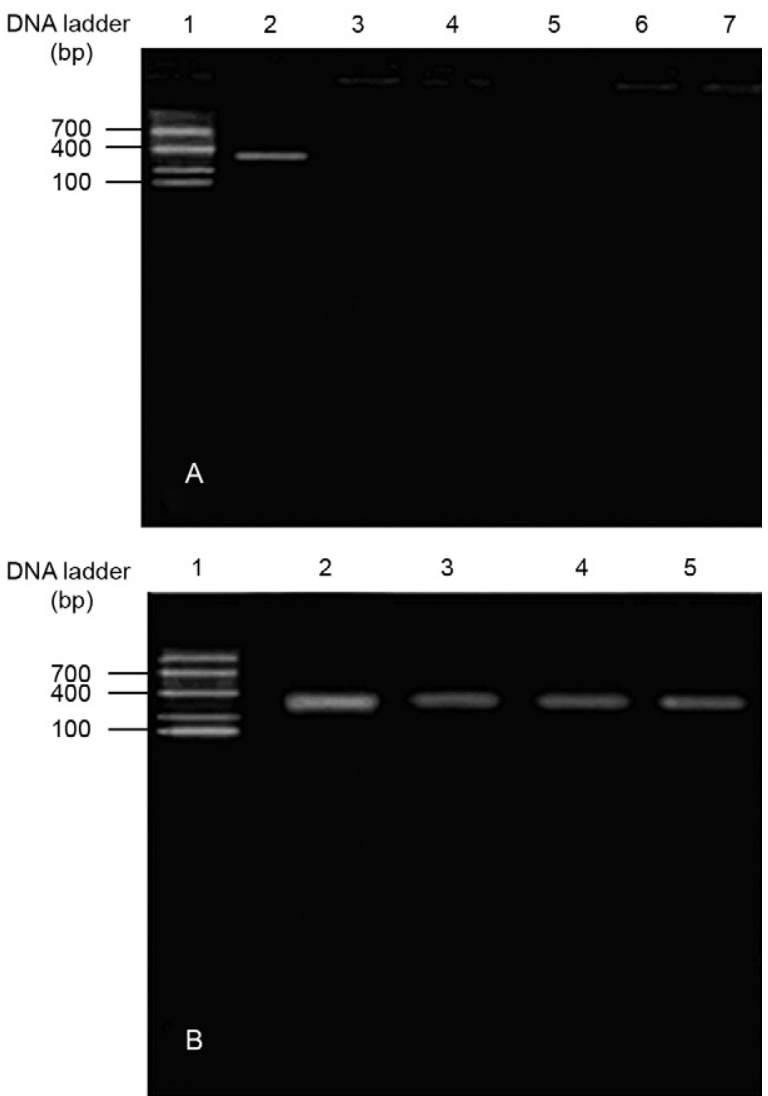

Fig. 2: agarose gel electrophoresis of polymerase chain reaction (PCR) products using species-specific primers to amplify. A: Biomphalaria glabrata internal transcribed spacer (ITS)2 [Lane 1: 100-bp DNA ladder; 2: B. glabrata lab. strain; 3-7: Biomphalaria snails from five different field localities (3: Giza; 4: Fayoum: 5: Kafr El-Sheikh; 6: Damietta; 7: Ismailia)]; B: Biomphalaria alexandrina ITS1 [Lane 1: 100-bp DNA ladder; 2: B. alexandrina Schistosome Biological Supply Center snails; 3-5: Biomphalaria snails from three different field localities (3: Giza; 4: Fayoum; 5: Kafr El-Sheikh)].




$D N A$ analysis using RAPD-PCR - RAPD-PCR was used to investigate the genetic diversity among the $B$. alexandrina snail groups (SBSC, Giza, Fayoum, Kafr El-Sheikh, Ismailia and Damietta) using similarity coefficients and a dendrogram tree. All of the applied primers successfully amplified products from genomic DNA from pooled samples (3 snails) of each snail group. Only bands that showed clear amplification from the pooled samples were scored to ensure the reproducibility of the RAPD marker information. Amplifications using 4 primers (OPA-1, OPA-9, OPA-18 and LROR) produced RAPD fingerprints (Fig. 3A-D) with varying numbers of bands ranging in size from 123.6-796.6 bp, depending on the origin of the snail and the primer used.

The frequency of each band was considerably different. Three monomorphic bands (123.6 bp, $184.2 \mathrm{bp}$ and $406.2 \mathrm{bp}$ ) were recorded at a $100 \%$ frequency among the examined $B$. alexandrina snail groups, which were produced by OPA-18, LROR and OPA-9 primers, respectively. These bands were found in all snail groups and were considered to be characteristic bands for B. alexandrina snails. There were 59 bands that showed the lowest frequency (17\%) among the examined snail groups.

The number of amplified and polymorphic bands generated by each primer is shown in Table IV. The highest total number of bands ( 37 bands) was obtained using primer OPA-18, while the lowest number (16 bands) was obtained with the OPA-9 primer. The primers LROR and
OPA-1 amplified the same total number of bands (33). The highest number of polymorphic bands was recorded with primers OPA-18 and LROR, which produced 14 bands, while the lowest number (5 bands) was obtained with primer OPA-9.

Regarding the total number of bands amplified using all primers in each snail group, Ismailia snails showed the highest number of bands (24), while the lowest number (16 bands) was recorded for the SBSC and the Kafr El-Sheikh groups.

The specific detected fragments obtained from each snail group showed that primer OPA-1 amplified the highest number of specific fragments (26 fragments), producing six fragments with molecular weights ranging from 132-538 bp in SBSC snails, another six fragments with molecular weights of 215-622 bp for Giza snails and four bands for the Fayoum (230-506 bp) and Ismailia (265-779 bp) groups. Three fragments with different molecular weights were recorded for Kafr El-Sheikh and Damietta snails. The OPA-9 primer amplified only five specific fragments, one of $264 \mathrm{bp}$ for the SBSC snail group, two for the Giza group (302 bp and $269 \mathrm{bp}$ ), one fragment of molecular weight $270 \mathrm{bp}$ for the Ismailia group and one (308 bp) for the Damietta snail group.

The band polymorphisms detected with each primer used indicated that the highest level of polymorphism was obtained with primer OPA-1, which produced $100 \%$ polymorphism, while the lowest $(87.5 \%)$ was obtained with
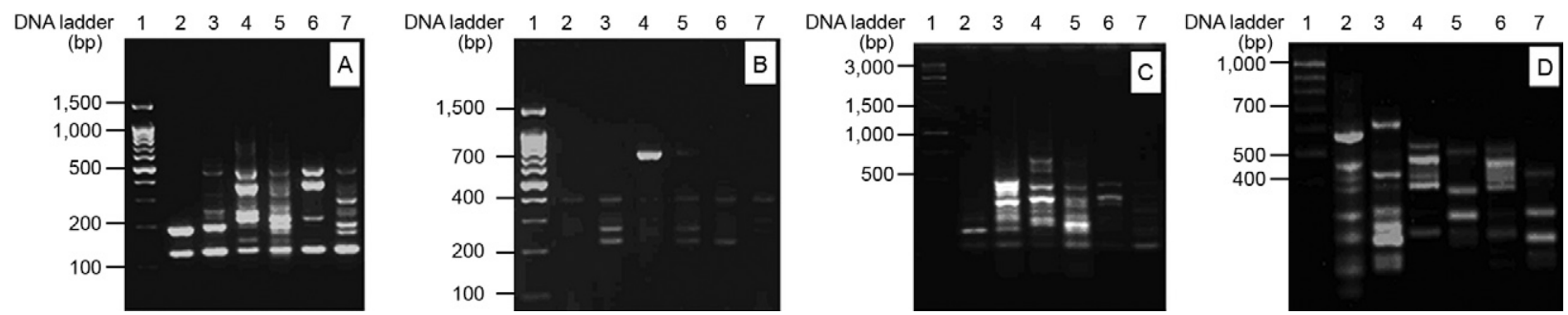

Fig. 3: agarose-gel electrophoresis of randomly amplified polymorphic DNA products generated in the six Biomphalaria alexandrina groups investigated with four different arbitrary primers: A: OPA-18; B: OPA-9; C: LROR; D: OPA-1; Lane 1: X174 DNA ladder; 2: Schistosome Biological Supply Center; 3: Giza; 4: Fayoum; 5: Ismailia; 6: Kafr El-Sheikh; 7: Damietta.

TABLE IV

List of primers and number of bands for each Biomphalaria alexandrina snail group investigated with four different random primers

\begin{tabular}{|c|c|c|c|c|c|c|c|c|c|}
\hline \multirow[b]{2}{*}{ Primer } & \multicolumn{6}{|c|}{ Number of amplified bands } & \multirow[b]{2}{*}{ Total } & \multirow{2}{*}{$\begin{array}{l}\text { Amplified } \\
\text { bands }\end{array}$} & \multirow{2}{*}{$\begin{array}{c}\text { Polymorphic } \\
\text { bands }\end{array}$} \\
\hline & SBSC & Giza & Fayoum & Ismailia & Kafr El-Sheikh & Damietta & & & \\
\hline OPA-18 & 3 & 6 & 8 & 8 & 5 & 7 & 37 & 24 & 14 \\
\hline OPA-9 & 2 & 4 & 2 & 4 & 2 & 2 & 16 & 8 & 5 \\
\hline LROR & 3 & 6 & 8 & 7 & 4 & 5 & 33 & 18 & 14 \\
\hline OPA-1 & 8 & 7 & 4 & 5 & 5 & 4 & 33 & 29 & 7 \\
\hline Total & 16 & 23 & 22 & 24 & 16 & 18 & 119 & 89 & 40 \\
\hline
\end{tabular}

SBSC: Schistosome Biological Supply Center. 
primer OPA-9. The number of amplified bands per primer varied from eight bands (with primer OPA-9) to 29 bands (with primer OPA-1), with a mean of 22.25 (Table V).

Genetic relationships among different B. alexandrina snail groups - The RAPD marker differences among the pooled DNA samples from each $B$. alexandrina group were analysed to determine the genetic relationships among populations. The estimated similarity coefficients among the $B$. alexandrina groups ranged from $0.56-0.72$. The highest value $(0.72)$ was recorded between the Ismailia and Kafr El-Sheikh groups, while the lowest (0.56) was detected between the SBSC and the Ismailia groups (Table VI).

An UPGMA dendrogram was produced including all of the DNA bands obtained from all of the tested primers for the six B. alexandrina snail groups (Fig. 4). The dendrogram showed three major groups. The first major group contained two groups, SBSC and Giza. The second major group was split into two subgroups, with the first including only the Fayoum group and the second containing two snail groups (Ismailia and Kafr El-Sheikh). The third major group included only the Damietta snail group.

\section{TABLE V}

Comparison of the bands polymorphism with each random primer used

\begin{tabular}{|c|c|c|c|c|}
\hline Gel polymorphism & OPA-18 & OPA-9 & LROR & OPA-1 \\
\hline Unique bands (n) & 17 & 5 & 13 & 26 \\
\hline $\begin{array}{l}\text { Polymorphic } \\
\text { (without unique) (n) }\end{array}$ & 6 & 2 & 4 & 3 \\
\hline $\begin{array}{l}\text { Polymorphic } \\
\text { (with unique) (n) }\end{array}$ & 23 & 7 & 17 & 29 \\
\hline Monomorphic bands (n) & 1 & 1 & 1 & 0 \\
\hline Total of bands (n) & 24 & 8 & 18 & 29 \\
\hline Polymorphism (\%) & 95.8 & 87.5 & 94 & 100 \\
\hline Mean of band frequency & 0.257 & 0.334 & 0.306 & 0.190 \\
\hline
\end{tabular}

SBSC: Schistosome Biological Supply Center.

\section{TABLE VI}

Similarity coefficients among six Biomphalaria alexandrina groups from SBSC and five Egyptian governorates based on RAPD-PCR profiles

\begin{tabular}{|c|c|c|c|c|c|}
\hline & SBSC & Giza & Fayoum & $\begin{array}{c}\text { Kafr } \\
\text { El-Sheikh }\end{array}$ & Ismailia \\
\hline Giza & 0.66 & & & & \\
\hline Fayoum & 0.62 & 0.60 & & & \\
\hline Kafr El-Sheikh & 0.69 & 0.68 & 0.67 & & \\
\hline Ismailia & 0.56 & 0.60 & 0.67 & 0.72 & \\
\hline Damietta & 0.64 & 0.58 & 0.59 & 0.69 & 0.59 \\
\hline
\end{tabular}

RAPD-PCR: random amplification of polymorphic DNApolymerase chain reaction; SBSC: Schistosome Biological Supply Center.
Impact of geographic distances on infection rates and similarity coefficients between $B$. alexandrina groups from the five governorates and $B$. alexandrina from $S B S C$ - In the present study, both $S$. mansoni ova and $B$. alexandrina snails were obtained from SBSC and were Egyptian strains originally obtained from Giza. Therefore, the distance between SBSC (source of parasite) and Giza was considered to be $0 \mathrm{~km}$ (Fig. 5). A negative correlation was observed between the infection rates of the different snail groups with the distance between their corresponding governorates and the source of the parasite (Fig. 6A) $(r=-0.664, p<0.01)$.

The infection rates of the different snail groups and their similarity coefficients with B. alexandrina (SBSC) were found to be positively correlated (Figs 5, 6B) (r $=0.724, \mathrm{p}<0.01$ using RAPD-PCR profiles). Moreover,

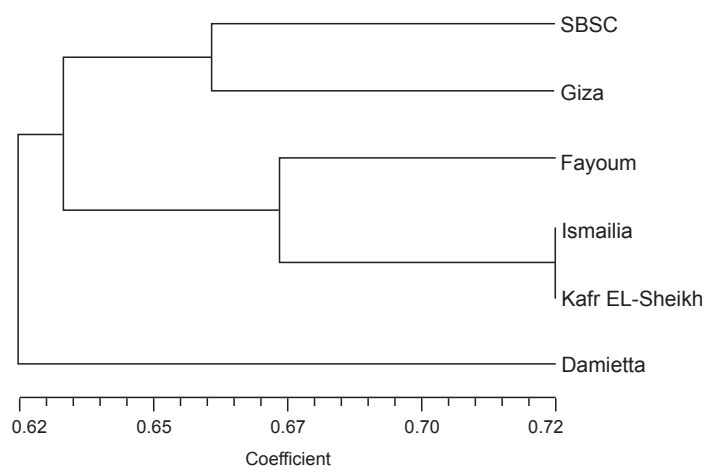

Fig. 4: unweighted pair group method with arithmetic average cluster analysis showing the diversity and relationship among six Biomphalaria alexandrina groups from Schistosome Biological Supply Center and five Egyptian governorates based on random amplification of polymorphic DNA-polymerase chain reaction profiles.



Fig. 5: relationships between the distance, similarity coefficients (B) and susceptibility to Schistosoma mansoni [Schistosome Biological Supply Center (SBSC)] infection of different Biomphalaria alexandrina groups from different localities compared to reference hostparasite system form SBSC. A: infection rate. 



Fig. 6: correlation between distances and infection rates (A), similarity coefficients and infection rates (B) and distance and similarity coefficients (C) of different Biomphalaria alexandrina groups.

negative correlations were obtained between the similarity coefficients of SBSC B. alexandrina snails with different snail groups and the distance to their corresponding governorate $(\mathrm{r}=-0.56, \mathrm{p}<0.05$ using RAPD-PCR profiles) (Figs 5, 6C).

\section{DISCUSSION}

This study demonstrated clear differences in susceptibility to $S$. mansoni infection, as well as genetic variation between populations of $B$. alexandrina snails. There was no evidence of the presence of $B$. glabrata or hybrids found in the analyses described herein. These findings have significant implications regarding the understanding of the relationship between genetic diversity and sus- ceptibility to parasitism, both in the context of B. alexandrina in Egypt as well as in other areas where intestinal schistosomiasis continues to be a public health problem.

Species identification of Biomphalaria - B. alexandrina, B. glabrata and hybrids between these species have all been previously reported to occur on the Nile Delta in Egypt (Yousif et al. 1996, Kristensen et al. 1999). Specifically, Kristensen et al. (1999) utilised RAPD-PCR to differentiate species and populations of Biomphalaria from Egypt and other countries and confirmed that both B. glabrata and B. alexandrina can be found on the Nile Delta and it appeared that hybridisation may be occurring between these two species. However, in the present study, species-specific PCR assays were performed to identify Biomphalaria snails collected from the field. According to the results of these assays, all of the Biomphalaria snails collected from the field were $B$. alexandrina.

This finding agrees with results reported by Lotfy et al. (2005a), who found no evidence of the presence of B. glabrata or of hybrids of $B$. alexandrina with $B$. glabrata in snail samples collected from the Nile Delta or nearby (including 8 samples from the Giza, Qualuobiya and Kafr El-Sheikh). These results, in combination with the findings presented here, suggest that B. glabrata may not have persisted on the Nile Delta, though further surveys should be conducted to verify if this is the case. In the same context, Abou-El-Naga et al. (2011) conducted morphological and molecular studies in reference $B$. alexandrina, $B$. glabrata and hybrid snails, as well as the first generation $\left(\mathrm{F}_{1}\right)$ of Biomphalaria snails from two areas in the Alexandria. Their morphological analyses included both external shell morphology and the internal anatomy of the renal ridge and their molecular analysis used a species-specific PCR technique. The results of these authors demonstrated that there was an absence of $B$. glabrata and the hybrid snails in Alexandria water channels. Removal of B. glabrata, which is an extremely susceptible host of $S$. mansoni, would be an important step in the fight to reduce schistosomiasis transmission in the Nile Delta region.

Population-level susceptibility to S. mansoni - In the present study, survival and infectivity rates and cercarial output parameters for B. alexandrina snails $\left(\mathrm{F}_{1}\right)$ originally obtained from Giza, Fayoum, Kafr El-Sheikh, Ismailia, Damietta and SBSC and infected with S. mansoni from SBSC were evaluated. Snail progenies usually reflect the same pattern of susceptibility as the parent snails (El-Khayat et al. 2005). The present results show clear differences in the degree of susceptibility to infection with the $S$. mansoni strain from SBSC among snail populations originating from various localities in Egypt. B. alexandrina from SBSC and Giza exhibited the highest degrees of susceptibility among the snail populations studied during this investigation. The infection rates of snails from these populations were $50.3 \%$ and $43.3 \%$, respectively. These variations in susceptibility agree with the findings of Frandsen (1979), who reported that $B$. alexandrina snails from various localities showed different susceptibility rates to a strain of $S$. mansoni. In the same context, Bakry (2009) reported that B. alexandrina 
snails from Damietta were less susceptible to infection with an Egyptian strain of $S$. mansoni (Giza) than $B$. alexandrina from Fayoum and Giza.

The higher infection rates exhibited by the SBSC (50.3\%) and Giza (43.3\%) snails reflect a higher susceptibility to schistosome infection as the source of both the snails and the parasite are considered to be the same. This agrees with the theory of local adaptation of the parasite to its local snail host (sympatric compatibility) (Maning et al. 1995, Lively 1999). In a few instances, however, this generalisation does not apply and less compatibility exists between a snail population and its local parasite strain (Cridland 1968, Mohamed 1987). In the present study, the lowest infection rate of only $15 \%$ was recorded in Fayoum snails, which was an unexpected finding because of the proximity of Fayoum to the origin of the parasite (Giza). This may be attributed to the geographic location of the Fayoum, which is considered to be an area isolated from the Nile Delta. This is in agreement with Sapp and Loker (2000), who suggested that the geographic isolation of the parasite and snail strains is the cause of the inability of Schistosoma douthitti to develop in Lymnaea stagnalis. Additionally, Coelho and Bezerra (2006) noted that some lineages or geographic isolates of the same species of Biomphalaria present great variation in their susceptibility to the parasite. For example, a geographic lineage of $B$. tenagophila isolated at the Biological Reservoir in Taim (Rio Grande do Sul, Brazil) was found to be completely resistant to the development of all tested $S$. mansoni isolates (obtained after passage through hamsters and $B$. glabrata at the Snail Biology and Parasite Research Laboratory at the Federal University of Ceará, Brazil).

RAPD-PCR methods for determining population genetic diversity - The present study demonstrates that a short primer of 10-20 bp nucleotides can be used to reproducibly amplify segments of DNA from different $B$. alexandrina groups. The greatest total number of bands (37 bands) was obtained using primer OPA-18, while the lowest number was obtained with the OPA-9 primer (16 bands). Ismailia snails exhibited the greatest number of bands (24), while the lowest number (16 bands) was recorded for the SBSC and Kafr El-Sheikh snail groups. The identification of polymorphic bands was based on a comparison of banding patterns on the same gel for each of the six snail groups investigated (Larson et al. 1996). The number polymorphic bands obtained was highest with primers OPA-18 and LROR (14 polymorphic bands) and lowest with primer OPA-9 (5 bands). Employing an equivalent sequence of oligonucleotides, Vidigal et al. (1994) detected polymorphic bands in individuals of $B$. glabrata species collected from different sites in Brazil. However, the results obtained here using primer OPA-18, which produced numerous polymorphic bands in the $B$. alexandrina groups investigated, differ from the findings obtained by Abu El-Enin (2004) who reported that the OPA-18 primer was the only reproducible marker for identifying different strains of Biomphalaria in Egypt.

The greatest number of specific fragments obtained using all of the tested primers was recorded in snails of the Giza and Damietta groups (12 fragments), while the lowest (5 fragments) was reported for the Kafr El-Sheikh snails. Regarding the band polymorphisms obtained with each primer used, the highest amount of polymorphism was obtained with primer OPA-1, which showed $100 \%$ polymorphism. This primer may be useful in differentiating between different $B$. alexandrina snails throughout the governorates, as it produced the highest number of specific fragments for each group of snails. The estimated similarity coefficients among $B$. alexandrina groups based on RAPD profiles ranged from 0.56-0.72. The dendrogram constructed including all DNA fragments produced by the four primers among the six $B$. alexandrina groups showed three major groups. The first contained the SBSC and Giza snail groups. The second split into two subgroups: one included the Fayoum snails and the other the Ismailia and Kafr El-Sheikh snails. The third major group contained only snails obtained from Damietta. Nevertheless, these data are not sufficient to indicate that the close populations in the dendrogram may have a common origin, whereas the most distant populations might be introduced from other locations.

Relationship between geographic distance and susceptibility - In the present study, the impact of geographic distances on the infection rates and similarity coefficients between different $B$. alexandrina snail groups from the five investigated governorates and $B$. alexandrina from SBSC was evaluated. A negative correlation was observed between the infection rates in different snail groups with the distance between their corresponding governorates and the source of the parasite (Giza) $(r=-0.664, p<0.01)$. Furthermore, the infection rates of snails from different governorates were found to be positively correlated with their similarity coefficients with reference to control B. alexandrina snails (SBSC) (r $=0.724, \mathrm{p}<0.01$ using RAPD-PCR profiles). Moreover, negative correlations were obtained between the similarity coefficients of SBSC B. alexandrina snails with the snail groups of different governorates and the distance to their corresponding governorate $(r=-0.56, p<0.05$ using RAPD-PCR profiles).

This phylogeographical pattern may be partly related to the geographical distribution of these populations and allows these correlations between genetic variability and geographic distance to be established. This finding confirms that not all Biomphalaria populations are equally susceptible to $S$. mansoni and that susceptibility varies among snails according to genetic variation, immune system status and geographic areas in which both the snails and the trematode occur (Richards \& Shade 1987). Many investigators have reported an expectation that a particular strain of snails should be better adapted to local parasites than parasites from other regions (Paraense \& Correa 1963, Sturrock \& Sturrock 1970). However, Cridland (1968) stated that although the distance from Nawa to Qualuob (Egypt) is short, snail colonies from Nawa exhibit a low-to-moderate susceptibility to $S$. mansoni infection, which is approximately one-third as high as that of a colony from Qualuob, and concluded that there is no correlation between the degree of susceptibility of snails to infection with S. mansoni and the distances separating the snail populations. Additionally, Barbosa and Figueiredo (1970), Romero-Morrell and 
Marta (1978) and Vera et al. (1990) claimed that when parasite-snail compatibility is studied in the laboratory, no correlation is generally found between the degree of susceptibility and the geographical distance separating the snails and the parasites.

The variation observed in the infection rate, which ranged from $50.3 \%$ in the sympatric host-parasite combination (SBSC) to $15 \%$ in the allopatric combination (parasite from SBSC-TBRI and snails from the Fayoum), is dependent not only on geographical distance, but also on genetic variability as a positive correlation was found between similarity coefficients obtained using RAPDPCR and the infection rates of different snail groups. Variation in the susceptibility of the snail hosts of schistosomes to infection with allopatric parasite strains is a well-documented phenomenon, which was first noted by Vogel (1941) and subsequently verified by numerous investigators. Michelson and DuBois (1978) suggested that this phenomenon cannot be restricted to distantly geographically separated snail strains. Additionally, Wiehn et al. (2002) demonstrated that parasite establishment in intermediate hosts can vary significantly based on host genetics. Narang et al. (1981) noted that inter-population genetic variability might result in differences in susceptibility to $S$. mansoni infection. Moreover, Mulvey and Vrijenhoek (1981) concluded that these variations could have implications in experiments where genetic uniformity of the studied organisms is necessary. Knight et al. (2000) found that there were different genetic strains of a single species of snails from the same locality that exhibited varying degrees of resistance and that even among susceptible stocks, certain individuals were more resistant than others. Moreover, Abdel-Hamid et al. (2006) studied genetic variations between $B$. alexandrina strains that are susceptible and resistant to Schistosoma infection using a RAPD-PCR analysis technique and showed that $39.8 \%$ of the examined snails collected from the field were resistant, while $60.2 \%$ of these snails showed high infection rates. In addition, Ittiprasert et al. (2010) claimed that the resistance or susceptibility of the snail host $B$. glabrata to $S$. mansoni infection is determined by the genetics of both the snail and the parasite. Although Mendelian genetics governs adult resistance to infection, juvenile resistance and susceptibility are complex traits.

In conclusion, all of the Biomphalaria snails collected from sampling sites in five Egyptian governorates (Giza, Fayoum, Kafr El-Sheikh, Ismailia and Damietta) were found to be $B$. alexandrina. The $B$. alexandrina groups included in this study showed variable $S$. mansoni infection rates according to their geographic origin and when DNA from these snails was analysed via RAPD-PCR, it was found that these variations in infectivity, as well as the differences in the similarity coefficients among these snails are dependent not only on the geographical distribution of the snails and the parasite, but also on the genetic variability of the snails.

\section{ACKNOWLEDGEMENTS}

To Dr Claire J Standley (Ecology and Evolutionary Biology, Princeton University, Princeton, NJ, USA), for her critical reading, helpful discussions and suggestions during the preparation of this manuscript.

\section{REFERENCES}

Abdel-Hamid AH, de Molfetta JB, Fernandez V, Rodrigues V 1999. Genetic variation between susceptible and non-susceptible snails to Schistosoma mansoni infection using random amplified polymorphic DNA analysis (RAPDs). Rev Inst Med Trop Sao Paulo 41: 291-295.

Abdel-Hamid A-HZ, Rawi SM, Arafa AF 2006. Identification of a genetic marker associated with the resistance to Schistosoma mansoni infection using random amplified polymorphic DNA analysis. Mem Inst Oswaldo Cruz 101: 863-868.

Abou-El-Naga IF, El-Nassery SMF, Allam SR, Shaat EA, Mady RFM 2011. Biomphalaria species in Alexandria water channels. Parasitol Int 60: 247-254.

Abu El-Enin HM 2004. Biological studies on different forms of Biomphalaria snails (Pulmonata: Planorbidae) in Egypt with relation to their molecular genetics and compatibility to infection with Schistosoma mansoni, PhD Thesis, Fac Sci Ain Shams Univ Egypt, 127 pp.

Bakry FA 2009. Genetic variation between Biomphalaria alexandrina and Biomphalaria glabrata snails and their Infection with Egyptian strain of Schistosoma mansoni. J App Sci Res 5: 1142-1148.

Barbosa FS, Figueiredo T 1970. Susceptibility of snail intermediate hosts of Schistosoma from northeastern Brazil to the infection with Schistosoma mansoni. Rev Inst Med Trop Sao Paulo 12: 198-206.

Borowsky L, Mcclelland M, Cheng R, Welsh J 1995. Arbitrarily primed DNA fingerprinting for phylogenetic reconstruction in vertebrates: the Xiphophorus model. Mol Biol Evol 12: 1022-1032.

Caldeira RL, Jannotti-Passos LK, Carvalho OS 2009. Molecular epidemiology of Brazilian Biomphalaria: a review of the identification of species and the detection of infected snails. Acta Trop 111: 1-6.

Chernin E 1970. Behavioural responses of miracidia of Schistosoma mansoni and other trematodes to substances emitted by snails. J Parasitol 56: 287-296.

Chernin E, Dunavan CA 1962. The influence of host-parasite dispersion upon the capacity of Schistosoma mansoni miracidia to infection Australorbis glabratus. Amer J Trop Med Hyg 11: 455-471.

Clark AG, Lanigan MS 1993. Prospects for estimating nucleotide divergence with RAPDs. Mol Biol Evol 10: 1096-1111.

Coelho JR, Bezerra FSM 2006. Compatibility of Biomphalaria tenagophila with Schistosoma mansoni: a study of homologous plasma transference. Mem Inst Oswaldo Cruz 101: 111-112.

Cridland CC 1968. Results of exposure of batches from highly susceptible and less susceptible strains of Biomphalaria alexandrina from Egypt to strains of Schistosoma mansoni from Cairo and Alexandria. Bull Wld Hlth Org 39: 955-961.

DeJong RJ, Morgan JAT, Paraense WL, Pointier JP, Amarista M, Ayeh-Kumi PF, Babiker A, Barbosa CS, Bremond P, Pedro Canese A, de Souza CP, Dominguez C, File S, Gutierrez A, Incani RN, Kawano T, Kazibwe F, Kpikpi J, Lwambo NJ, Mimpfoundi R, Njiokou F, Noel Poda J, Sene M, Velasquez LE, Yong M, Adema CM, Hofkin BV, Mkoji GM, Loker ES 2001. Evolutionary relationships and biogeography of Biomphalaria (Gasteropoda: Planorbidae) with implications regarding its role as host of the human blood fluke, Schistosoma mansoni. Mol Biol Evol 18: 2225-2239.

El-Khayat HM, Saber MA, Abu El-Hassan AA 2005. Study of the susceptibility of Biomphalaria alexandrina collected from five different localities in Egypt to infection with local strain of Schistosoma mansoni. Egypt J Schist End Infec Dis 27: 39-50.

Frandsen F 1979. Studies on the relationship between Schistosoma and their intermediate hosts. III. The genus Biomphalaria and Schistosoma mansoni from Egypt, Kenya, Uganda, West Indies 
and Zaire (two different strains from Katanga and Kinshasha). J Helminthol 53: 321-348.

Grech K, Watt K, Read AF 2006. Host-parasite interactions for virulence and resistance in a malaria model system. J Evol Biol 19: 1620-1630.

Grosholz ED 1994. The effects of host genotype and spatial distribution on trematode parasitism in a bivalve population. Evolution 48: $1514-1524$.

Ittiprasert W, Miller A, Myers J, Nene V, El-Sayed NM, Knight M 2010. Identification of immediate response genes dominantly expressed in juvenile resistant and susceptible Biomphalaria glabrata snails upon exposure to Schistosoma mansoni. Mol Biochem Parasitol 169: 27-39.

Knight M, Miller NA, Patterson CN, Rowe CG, Michaels G, Carr D, Richards CS, Lewis FA 1999. The identification of markers segregating with resistance to Schistosoma mansoni infection in the snail Biomphalaria glabrata. Proc Nat Acad Sci USA 96: $1510-1515$

Knight M, Ongele E, Lewis FA 2000. Molecular studies of Biomphalaria glabrata, an intermediate hosts of Schistosoma mansoni. Inter J Parasitol 30: 535-541.

Kristensen TK, Yousif F, Raahauge P 1999. Molecular characterization of Biomphalaria species in Egypt. J Moll Stud 65: 133-136.

Langand J, Théron A, Pointier JP, Delay B, Jourdane J 1999. Population structure of Biomphalaria glabrata, intermediate snail host of Schistosoma mansoni in Guadeloupe Island using RAPD markers. J Moll Stud 65: 425-433.

Larson SE, Anderson PL, Miller NA, Cousin CE, Richards CS, Lewis FA, Knight M 1996. Use of RAPD-PCR to differentiate genetically defined lines of intermediate host Schistosoma mansoni, Biomphalaria glabrata. J Parasitol 82: 237-244.

Lewis FA, Patterson CN, Grzywacz C 2003. Parasite susceptibility phenotypes of $\mathrm{F}(1)$ Biomphalaria glabrata progeny derived from interbreeding Schistosoma mansoni resistant and -susceptible snails. Parasitol Res 89: 98-101.

Lively CM 1999. Migration, virulence and the geographic mosaic of adaptation by parasites. Amer Nat 153: 34-47.

Lotfy WM, DeJong RJ, Abdel Kader AA, Loker ES 2005a. A molecular survey of Biomphalaria in Egypt: is B. glabrata present? Amer J Trop Med Hyg 73: 131-139.

Lotfy WM, DeJong RJ, Black BS, Loker ES 2005b. Specific identification of Egyptian Biomphalaria species and possible hybrids using the polymerase chain reaction based on nuclear and mitochondrial loci. Mol Cell Probes 19: 21-25.

Manning SD, Woolhouse ME, Ndamba J 1995. Geographic compatibility of the freshwater snail Bulinus globosus and schistosomes from the Zimbabwe highveld. Int J Parasitol 25: 37-42.

Michelson EA, DuBois L 1978. Susceptibility of Bahian population of Biomphalaria glabrata to an allopatric strain of Schistosoma mansoni. Amer J Trop Med Hyg 27: 782-786.

Miller F, Hussein M, Mancy KH, Hilbert MS, Monto AS, Barakat RM 1981. An epidemiological study of Schistosoma haematobium and $S$. mansoni infection in thirty-five rural Egyptian villages. Trop Geogr Med 33: 355-365.

Mohamed SH 1987. Studies on the relationships of snail genus Biomphalaria in Egypt with certain strains of Schistosoma mansoni, PhD Thesis, Fac Sci Ain Shams Univ Egypt, 193 pp.

Mulvey M, Vrijenhoek RC 1981. Genetic variation among laboratory strains of the planorbid snail Biomphalaria glabrata. Biochem Genet 19: 1169-1182.
Narang S, Narang N, Monteiro W, Almeida JMC 1981. Genetic differentiation between populations of Biomphalaria glabrata (Mollusca: Pulmonata) located in the state of Bahia and in the state of Minas Gerais (Brazil). Rev Bras Genet 4: 269-279.

Nie M 1987. Estimation of average heterozygosity and genetic distance from a small number of individuals Genetics 83: 583-590.

Ogunkanmi LA, Oboh B, Williams O, Monu G, Ogundipe OT 2009. Phylogenetic and genomic relationships in the genus Malus based on RAPDs. Afr J Biotech 8: 3387-3391.

Oliveira AL, Da Silva D, Zanotti-Magalhaes EM, Abdel-Hamid AZ, Ribeiro-Paes JT 2008. Schistosome/mollusk: genetic compatibility. Genet Mol Res 7: 518-526.

Paraense WL, Correa LR 1963. Variation in susceptibility of population of Australorbis glabratus to a strain of Schistosoma mansoni. Rev Inst Med Trop Sao Paulo 5: 15-22.

Richards CS, Shade PC 1987. The genetic variation in Biomphalaria glabrata and Schistosoma mansoni. J Parasitol 3: 1146.

Rohlf FJ 2000. NYSYS-pc: numerical taxonomy and multivariate analysis system, version 2.10L, Schanket, New York.

Romero-Morrell J, Marta CB 1978. Estudio de la susceptibilidad de una cepa de Biomphalaria glabrata de Venezuela a la infeccion con dos diferentes cepas de Schistosoma mansoni. Rev Inst Med Trop Sao Paulo 20: 318-322.

Saap KK, Loker ES 2000. Mechanism underlying digenean-snail specificity: role of miracidial attachment and host plasma factor. J Parasitol 86: 1012-1019.

Sambrook J, Fritsch EF, Mainatis T 1989. Molecular cloning, Vols. I, II, III, Cold Spring Harbor Laboratory, New York, 545 pp.

Saoud MF 1965. Comparative studies on the characteristics of some geographical strains of Schistosoma mansoni in mice and hamster. J Helminthol 39: 101-112.

Sokal RS, Rohlf FJ 1995. Biometry: the principles and practice of statistics in biological research, WH Freeman and Co, New York, $887 \mathrm{pp}$.

Sturrock BM, Sturrock RF 1970. Laboratory studies on the hostparasite relationship of Schistosoma mansoni and Biomphalaria glabrata from St. Lucia, West Indies. Ann Trop Med Parasitol 64: $357-363$.

Teodoro TM, Janotti-Passos LK, Carvalho OS, Caldeira RL 2010. Occurrence of Biomphalaria cousini (Mollusca: Gastropoda) in Brazil and its susceptibility to Schistosoma mansoni (Platyhelminths: Trematoda). Mol Phylog Evol 57: 144-151.

Theron A, Pages JR, Rognon A 1997. Schistosoma mansoni: distribution patterns of miracidia among Biomphalaria glabrata snail as related to host susceptibility and sporocyst regulatory processes. Exp Parasitol 85: 1-9.

Trouve S, Degen L, Goudet J 2005. Ecological components and evolution of selfing in the freshwater snails, Galba truncatula. J Evol Biol 18: 358-370

Trouve S, Degen L, Renaud F, Goudet J 2003. Evolutionary implications of a high selfing rate in the freshwater snail Lymnaea truncatula. Evolution 57: 2303-2314.

Vera C, Jourdane J, Sellin B, Combes C 1990. Genetic variability in the compatibility between Schistosoma haematobium and its potential vectors in Niger. Epidemiological implications. Trop Med Parasitol 41: 143-148.

Vidigal TH, Dias Neto E, Carvalho DA, Simpson AJ 1994. Biomphalaria glabrata: Extensive genetic variation in Brazilian isolates revealed by random amplified polymorphic DNA analysis. Exp Parasitol 79: 187-194. 
Vogel H 1941. Infektions versuche and verschiedenen Bilharzia-Zwischenwirten mit einem einselnen Mirazidum von Bilharzia mansoni und Biomphalaria japonica. Zentr Bakt I Abst Orig 148: 29-35.

Vrijenhoek RC, Graven MA 1992. Population genetics of Egyptian Biomphalaria alexandrina (Gastropoda: Planorbidae). J Hered 83: 255-261.

Webster JP, Jones C, Ndamba J, Wolhouse ME, Noble L 1996. Detection of genetic diversity within snail intermediate hosts of the species Biomphalaria pfeifferi using random amplified polymorphic DNA markers (RAPD), Proceedings of A Status of Research on Medical Malacology in Relation to Schistosomiasis in Africa, Zimbabwe, August 1995, p. 205-211.

Welsh J, McClelland M 1990. Finger printing genomes using PCR with arbitrary primers. Nucleic Acid Res 18: 7213-7218.

Wiehn J, Kopp K, Rezzonico S, Karttunen S, Jokela J 2002. Familylevel covariation between parasite resistance and mating system in a hermaphroditic freshwater snail. Evolution 56: 1454-1461.
Williams JG, Kubelick AR, Livak KJ, Rafolski JA, Tingey SV 1990. DNA polymorphisms amplified by arbitrary primers are useful as genetic markers. Nucleic Acid Res 18: 6531-6535.

Winnepennickx B, Backeljau T, Wacbier R 1993. Extraction of high molecular weight DNA from mollusca. Trends Genetics 9: 407.

Yousif F, Haroun N, Ibrahim A, El-Bardicy S 1996. Biomphalaria glabrata: a new threat for schistosomiasis transmission in Egypt. J Egypt Soc Parasitol 26: 191-205.

Yousif F, Ibrahim A, Abdel Kader A, El-Bardicy S 1998a. Invasion of the Nile Valley in Egypt by a hybrid of Biomphalaria glabrata and Biomphalaria alexandrina, snail vectors of Schistosoma mansoni. J Egypt Soc Parasitol 28: 569-582.

Yousif F, Ibrahim A, El-Bardicy SN 1998b. Compatibility of Biomphalaria alexandrina, Biomphalaria glabrata and a hybrid of both to seven strains of Schistosoma mansoni from Egypt. J Egypt Soc Parasitol 28: 863-881.

Zar JH 1999. Biostatistical analysis, 4th ed., Prentice-Hall International Inc, Englewood Cliffs, 663 pp. 